\title{
Physical and Functional Mapping of Two Cointegrate Plasmids Derived from RP4 and TOL Plasmid pDK1
}

\author{
By LINDA E. SHAW AND PETER A. WILliAMS* \\ Department of Biochemistry, School of Biological Sciences, University College of North Wales, \\ Bangor, Gwynedd LL57 2UW, UK
}

(Received 14 March 1988)

\begin{abstract}
Cointegrate plasmids were formed in vivo between the broad-host-range R-plasmid RP4 and two catabolic plasmids derived from Pseudomonas putida HS1. One of these was the wild-type plasmid pDK1 encoding the complete inducible toluene/xylene (TOL) catabolic pathway and one was pDKT1, a deletion derivative of pDK 1 selected after growth of HS1 on benzoate and supporting growth on only toluene. The two plasmids formed, $\mathrm{pDK} 2$ and $\mathrm{pDKT} 2$ respectively, each consisted of a complete RP4 replicon in which was an insert of the parent plasmid DNA respectively 40 and $20 \mathrm{kbp}$ in size. The detailed restriction maps of the two plasmids were determined and many of the catabolic genes were located by subcloning and enzyme assay of recombinant plasmids in Escherichia coli and Pseudomonas hosts. The insert in pDK2 contained both operons of the catabolic pathway, the 'upper pathway' operon $(x y l C A B)$ and the meta pathway operon $(x y l D L E G F(I, J, K) H)$, and a region identified as having the function of the regulator gene $x y l S$. The insert in pDKT2 contained only the upper pathway operon and the regulatory region. Within each of the three coding regions there was great similarity with the same regions on TOL plasmids pWW0 and pWW53-4 apparent (a) by the same order of the genes, $(b)$ by a similar pattern of restriction sites and $(c)$ by hybridization studies. However, the order and orientations of the three coding regions differed from those previously described for both pWW0 and pWW53-4. The significance of these findings to the evolution of TOL plasmids is discussed.
\end{abstract}

\section{INTRODUCTION}

Strains of Pseudomonas isolated from natural environments with the ability to catabolize toluene and methyl-substituted toluenes (xylenes) via benzoate and methylbenzoates (toluates) and the meta-cleavage pathway almost always have the catabolic pathway encoded on a plasmid. Many such plasmids have been described (Williams \& Worsey, 1976; Yano \& Nishi, 1980 ; Kunz \& Chapman, 1981) and have been designated as TOL plasmids, the archetype and best studied of which is pWW0, originally found in P. putida mt-2 (Nakazawa \& Yokota, 1973; Williams \& Murray, 1974).

P. putida HS1 (also called PpC1) was isolated by Kunz \& Chapman (1981). During growth on benzoate HS1 spontaneously segregated a unique set of plasmid deletion mutants: one of these, PpCT1, retained the ability to grow on toluene but no longer supported growth on the substituted toluenes and metabolized the benzoate, formed from toluene by the plasmiddetermined enzymes, via the chromosomal $\beta$-ketoadipate (or ortho cleavage) pathway (Kunz \& Chapman, 1981).

In this paper we describe the in vivo construction of two cointegrate plasmids formed between the broad-host-range R-plasmid RP4 and both pDK1 and pDKT1, the plasmids in wild type $P$.

\footnotetext{
Abbreviations: BADH, benzyl alcohol dehydrogenase; BZDH, benzaldehyde dehydrogenase; C23O, catechol 2,3-oxygenase; HMSH, 2-hydroxymuconic semialdehyde hydrolase; HMSD, 2-hydroxymuconic semialdehyde dehydrogenase; 4OT, 4-oxalocrotonate tautomerase.
} 
putida $\mathrm{HS} 1$ and its segregant PpCT1 respectively. The two plasmids, designated $\mathrm{pDK} 2$ and pDKT2, have been mapped and the DNA derived from the catabolic plasmids has been extensively studied by cloning, subcloning and Southern blotting to locate the majority of the toluene/xylene pathway genes. The resulting physical map shows some major similarities to and significant differences from the isofunctional coding regions on TOL plasmids $\mathrm{pWW} 0$ and pWW53-4 (Keil et al., 1987a).

\section{METHODS}

Bacterial strains and plasmids. The Escherichia coli and Pseudomonas putida strains and the plasmids used or constructed are listed in Table 1.

Media and culture conditions. Bacteria were grown and maintained as described by Worsey \& Williams (1975), Keil et al. (1985a) and Keil et al. (1985b). P. putida strains carrying the cointegrate plasmids were maintained on minimal agar plates with $m$-toluate (pDK1) or toluene (pDKT1) as carbon sources with added kanamycin $\left(100 \mu \mathrm{g} \mathrm{ml}^{-1}\right)$. Carbenicillin, donated by Beechams, was added where appropriate at $2 \mathrm{mg} \mathrm{ml}^{-1}$.

Formation of $p D K 2$ and $p D K T 2$. The RP4::pDK1 plasmid pDK2 was constructed by transferring RP4 from $P$. putida AC34(RP4) into HS1 by conjugation on filters. One $\mathrm{Cb}^{r} \mathrm{Tc}^{r} \mathrm{Km}^{\mathrm{r}} \mathrm{Mtol}^{+}$transconjugant, shown to contain both RP4 and pDK1, was then used as a donor in a mating on filters with PaW340 as recipient: selection was made for transconjugants able to grow on $m$-toluate in the presence of streptomycin at $1 \mathrm{mg} \mathrm{ml}^{-1}$ (to select for PaW340 and to counterselect against HS1). All transconjugants examined contained single plasmids; PaW630, which was able to grow on both $m$-xylene and $m$-toluate and contained the smallest of the plasmids examined (pDK2), was used in this study. PaW637, containing the plasmid pDKT2, was formed from strain PpCT1 by essentially the same protocol but using selection for growth on toluene in place of $m$-toluate.

Enzyme assays. Enzymes were assayed in cell-free extracts using the same procedures as Sala-Trepat \& Evans (1971) and Worsey \& Williams (1975).

Plasmid and DNA manipulations. Plasmids pDK1, pDKT1, pDK2 and pDKT2 were extracted from Pseudomonas hosts according to Wheatcroft \& Williams (1981). pDK2, pDKT2, vector plasmids and recombinant plasmids were isolated from $E$. coli hosts by $\mathrm{CsCl}$ /ethidium bromide gradient centrifugation. Hydrolyses with restriction endonucleases, DNA ligations and transformation of $E$. coli with plasmid DNA were done by standard procedures (Maniatis et al., 1982). Both E. coli and P. putida strains were screened for the presence of small plasmids according to Holmes \& Quigley (1981). DNA-DNA hybridizations were performed as described by Keil et al. (1987a) after Southern (1975).

Mobilization of recombinant plasmids into P. putida. Recombinant plasmids with inserts in the broad-host-range vector pK T230 were mobilized from $E$. coli into $P$. putida using the unstable RP4 derivative plasmid pNJ5000 as described by Keil et al. $(1985 b)$.

\section{RESULTS}

\section{Characterization of cointegrate plasmids $p D K 2$ and $p D K T 2$}

Table 2 shows the sizes of DNA fragments obtained by digestion of pDK1, pDKT1, pDK2 and pDKT2 with restriction endonuclease HindIII: similar data have been obtained for enzymes $X h o \mathrm{I}, E c o \mathrm{RI}$ and $B a m \mathrm{HI}$ but are not presented here. Analysis of the results showed that pDK 2 contained 7 HindIII fragments, 15 XhoI fragments, 7 EcoRI fragments and 5 BamHI fragments identical in size to ones found in the parent $\mathrm{PDK} 1$ : it also contained novel fragments, not found in pDK1 or RP4, carrying the junctions between RP4 and the pDK1 insertion. The digests of pDKT2 also contained fragments identical in size to those from its parent pDKT1 : HindIII (4), XhoI (5), EcoRI (1) and BamHI (2). Most of these were also identical in size to fragments in pDK1. Again novel fragments were found which were not present in either pDKT1 or RP4.

Complete restriction maps for both cointegrate plasmids were constructed using the following methods: (1) single, double and triple digestions with the four endonucleases referred to above; (2) cloning all the HindIII fragments, many of the XhoI fragments and most of the BamHI fragments; (3) detailed restriction mapping of the cloned DNA using a larger bank of enzymes; and (4) cross-hybridization between cloned DNA by Southern blotting.

The map of pDK2 is shown in Fig. 1, in which the fragments are lettered alphabetically according to their position in the corresponding digests of $\mathrm{pDK} 1$. The map shows that about $40 \mathrm{kbp}$ of pDK1 DNA has been inserted into the $13.3 \mathrm{kbp} \mathrm{KpnI}$ fragment of RP4, between 
Table 1. Bacterial strains and plasmids

\begin{tabular}{|c|c|c|}
\hline Strain & Plasmid & Notes and references \\
\hline \multicolumn{3}{|c|}{ Escherichia coli strains } \\
\hline CA60 & & hsdR hsdM recBC derivative of $\mathrm{C} 600$ \\
\hline $\mathrm{C} 600$ & pNJ5000 & Grinter (1983) \\
\hline C600 & pKT230 & Bagdasarian et al. (1981) \\
\hline C600 & pBR325 & Prentki \& Kirsch (1982) \\
\hline ED8654 & & $h s d R h s d M^{+} \operatorname{trpR}$ met $^{-}$ \\
\hline \multicolumn{3}{|c|}{ Pseudomonas putida strains } \\
\hline HS1 & $\mathrm{pDK} 1$ & Kunz \& Chapman (1981) \\
\hline PpCT1 & pDKT1 & Kunz \& Chapman (1981) \\
\hline AC34 & RP4 & $\mathrm{Ade}^{-} \mathrm{Cb}^{r} \mathrm{Km}^{\mathrm{r}} \mathrm{Tc}^{r}$ (gift of C. J. Duggleby) \\
\hline PaW95 & & $\begin{array}{l}\text { Plasmid-free mutant in chromosomal benzoate cis-diol dehydrogenase } \\
\text { (Keil et al., 1985b) }\end{array}$ \\
\hline PaW130 & & Rif ${ }^{\top}$ plasmid-free derivative of $P$. putida $\mathrm{mt}-2$ (PaW1) (Keil et al., 1985a) \\
\hline PaW263 & pWW0-xylA & Franklin \& Williams (1980) \\
\hline PaW340 & & Trp-Str ${ }^{r}$ plasmid-free derivative of PaW1 (Jeenes \& Williams, 1982) \\
\hline PaW630 & pDK2 & RP4::pDK1 plasmid in PaW340 (this study) \\
\hline PaW637 & pDKT2 & RP4::pDKT1 plasmid in PaW340 (this study) \\
\hline PaW823 & pWW0-660 & pWW0 plasmid with $x y l C A B$ deletion (Lebens \& Williams, 1985) \\
\hline \multicolumn{3}{|c|}{ Recombinant plasmids } \\
\hline & pDK $1-3014$ & $2.1 \mathrm{kbp} X$ hoI fragment $\mathrm{X}$ of $\mathrm{pDK} 1$ in $\mathrm{pKT} 230$ \\
\hline & pDK $1-3042$ & $4.4 \mathrm{kbp} X h o \mathrm{I}$ fragment $\mathrm{I}$ of $\mathrm{pDK} 1$ in $\mathrm{pKT} 230$ \\
\hline & pDK $1-3059$ & $7.6 \mathrm{kbp}$ HindIII fragment $\mathrm{G}$ of pDK 1 in $\mathrm{pKT} 230$ \\
\hline & pDK $1-3060$ & $\begin{array}{l}6.1 \mathrm{kbp} S m a \mathrm{I} / \text { HindIII part of pDK } 1-3059 \text { generated by deletion of } 1.9 \mathrm{kbp} S m a \mathrm{I} \\
\text { fragment (one site on vector) }\end{array}$ \\
\hline & pDK2-3064 & $3.9 \mathrm{kbp}$ BamHI fragment D of pDK2 in pBR325 \\
\hline & pDK2-3067 & $15.5 \mathrm{kbp}$ HindIII fragment $\mathrm{A}$ of $\mathrm{pDK} 2$ in $\mathrm{pBR} 325$ \\
\hline & pDK2-3085 & Internal $4.6 \mathrm{kbp} S m a I$ subfragment of pDK2-3067 in pKT230 \\
\hline & pDK2-3087 & $15.5 \mathrm{kbp}$ HindIII insert of pDK2-3067 recloned into pKT230 \\
\hline & pDK2-3090 & $6.8 \mathrm{kbp}$ BamHI fragment $\mathrm{C}$ of pDK2 in pBR325 \\
\hline & pDK2-3091 & $\begin{array}{l}\text { BamHI insert of pDK2-3064 recloned into the unique (vector) } \\
\text { BamHI site of pDK2-3087 }\end{array}$ \\
\hline & pDK2-3092 & Internal $2.6 \mathrm{kbp} X$ hoI fragment of pDK2-3090 in pKT230 \\
\hline & pDK2-3095 & Internal 600 bp $B g I I I$ fragment deleted from pDK2-3064 \\
\hline & pDK2-3098 & Internal $3.0 \mathrm{kbp} S s t \mathrm{I}$ fragment of pDK2-3087 in pKT230 \\
\hline & pDK2-3100 & $\begin{array}{l}\text { The deleted } \text { BamHI insert of pDK2-3095 cloned into the unique (vector) } \\
\text { site of pDK2-3087 }\end{array}$ \\
\hline & pDK2-3107 & Internal $2.8 \mathrm{kbp} S m a \mathrm{I}$ fragment of pDK2-3087 in pKT230 \\
\hline & pDK 1-3109 & $2.9 \mathrm{kbp} X h o \mathrm{I}$ fragment $\mathrm{R}$ of $\mathrm{pDK} 1$ in $\mathrm{pKT} 230$ \\
\hline & pDK $1-3110$ & Internal $4 \cdot 1 \mathrm{kbp} P$ stI fragment of pDK1-3059 in pBR325 \\
\hline & pDK2-3111 & 3.7 kbp HindIII fragment from pDK $2-3090$ in pKT230 (contains $300 \mathrm{bp}$ of pBR325) \\
\hline & pDK2-3113 & Internal $4.3 \mathrm{kbp}$ SstI fragment of pDK2-3067 in pKT230 \\
\hline & pDK2-3114 & Internal $3.8 \mathrm{kbp} S s t \mathrm{I}$ fragment of pDK2-3090 in pKT230 \\
\hline & pDK $1-3117$ & $\begin{array}{l}2.7 \mathrm{kbp} \text { SmaI } / \text { BamHI part of pDK } 1-3060 \text { generated by deletion of internal } \\
4.3 \mathrm{kbp} \text { BamHI fragment (one site on vector) }\end{array}$ \\
\hline & pDK 1-3119 & $\begin{array}{l}9.5 \mathrm{kbp} \operatorname{SmaI} / \text { BamHI fragment formed when } B a m \mathrm{HI} \text { fragment } \mathrm{C} \text { is cloned into } \\
\text { unique BamHI site of pDK } 1-3117\end{array}$ \\
\hline
\end{tabular}

coordinates 11 and 14 as measured clockwise from its single EcoRI site (Lanka et al., 1983): as far as can be ascertained there has been no deletion of RP4 DNA in the cointegration.

The map of pDKT2 is shown in Fig. 2. The fragments are labelled according to the same convention as for $\mathrm{pDK} 2$, apart from HindIII-Kn and $X$ hoI-Dn, which are both novel fragments found in pDKT1 but not in pDK1. It is presumed that these are fragments formed originally in the deletion event which gave rise to the formation of $\mathrm{pDKT} 1$ from $\mathrm{pDK} 1$ during the benzoate selection (Kunz \& Chapman, 1981). In pDKT2 about $20 \mathrm{kbp}$ of pDKT1 DNA has been incorporated into the apparently complete RP4 replicon, but the site of insertion in this case is in the $1.8 \mathrm{kbp} \mathrm{KpnI}$ fragment of RP4 at about coordinate 38 from its EcoRI site.

A more detailed restriction map of the two TOL plasmid inserts in the cointegrates is shown in Fig. 3, together with the major subclones used in the determination of the catabolic gene locations. 


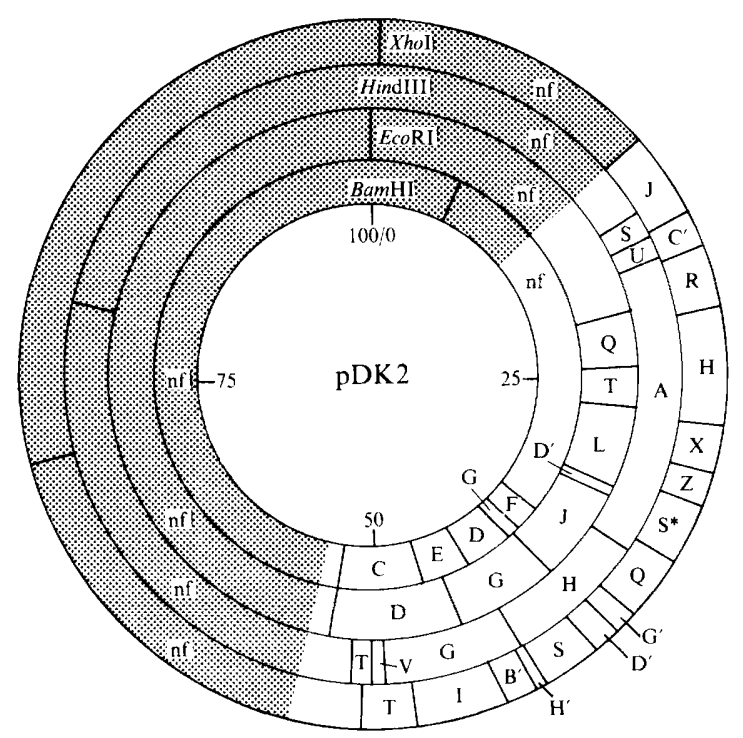

Fig. 1. Restriction map of pDK2. The fragments are labelled with letters corresponding to their positions in the digests of $\mathrm{pDK} 1$ (as Table 2). nf refers to novel fragments containing DNA from both pDK 1 and RP4. The shaded area represents the complete RP4 replicon. The scale is in kbp.

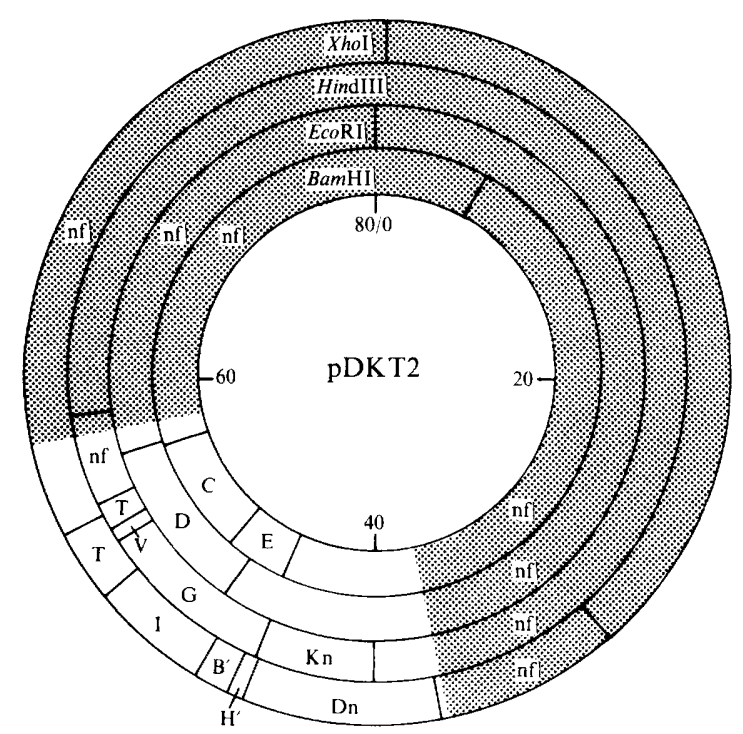

Fig. 2. Restriction map of pDKT2. The fragments are labelled with letters corresponding to their positions in the digests of pDKT1 (as Table 2). nf refers to novel fragments containing DNA from both RP4 and pDKT1. The shaded area represents the complete RP4 replicon. The scale is in kbp.

\section{Location of genes of $x y l C A B$ operon}

The results from assaying the enzymes of the 'upper pathway' encoded by recombinant plasmids carrying cloned genes are shown in Table 3.

Benzaldehyde dehydrogenase (BZDH, $x y l C$ ) can be detected in strains of $E$. coli containing plasmids pDK1-3042, pDK1-3059, pDK 1-3060 and pDK1-3110, but not in strains carrying pDK 1-3117 or pDK2-3090, and can therefore be located between coordinates 6 and $9 \cdot 4$. 
Table 2. Sizes of DNA fragments obtained by digestion of $p D K 1, p D K 2, p D K T 1$ and $p D K T 2$ with restriction endonuclease HindIII

\begin{tabular}{|c|c|c|c|c|c|c|c|}
\hline \multicolumn{2}{|c|}{ pDK1 } & \multicolumn{2}{|c|}{ pDK2 } & \multicolumn{2}{|c|}{ pDKT1 } & \multicolumn{2}{|c|}{ pDKT2 } \\
\hline Fragment & Size (kbp) & Fragment & Size (kbp) & Fragment & Size (kbp) & Fragment & Size (kbp) \\
\hline & & & & & & RP4n1* & $>60$ \\
\hline & & $\begin{array}{l}\text { RP4n2* } \\
\text { RP4n } 3^{*}\end{array}$ & $\begin{array}{l}\approx 38 \\
\approx 28\end{array}$ & & & & \\
\hline A & 15.5 & $\begin{array}{l}\mathrm{RP4n3^{* }} \\
\mathrm{A}\end{array}$ & $\approx 28$ & & & & \\
\hline B & 14.5 & & & B & 14.5 & & \\
\hline C & $12 \cdot 6$ & & & & & & \\
\hline D & $9 \cdot 8$ & & & D & $9 \cdot 8$ & & \\
\hline E & $9 \cdot 8$ & & & E & $9 \cdot 8$ & & \\
\hline $\mathrm{F}$ & $9 \cdot 1$ & & & $\mathrm{~F}$ & 9.1 & & \\
\hline G & 7.6 & G & $7 \cdot 6$ & G & 7.6 & G & $7 \cdot 6$ \\
\hline H & $7 \cdot 6$ & $\mathbf{H}$ & 7.6 & & & & \\
\hline I & 6.8 & & & I & 6.8 & & \\
\hline $\mathrm{J}$ & $6 \cdot 0$ & & & & & & \\
\hline K & $5 \cdot 5$ & & & & & & \\
\hline & & & & $\mathrm{Kn} \dagger$ & $5 \cdot 1$ & $\mathrm{Kn} \dagger$ & $5 \cdot 1$ \\
\hline & & & & $\operatorname{Ln} \dagger$ & $5 \cdot 1$ & & \\
\hline $\mathbf{L}$ & 3.9 & & & & & & \\
\hline $\mathbf{M}$ & & & & & & RP4n4* & 3.85 \\
\hline $\mathbf{N}$ & 2.8 & & & & & & \\
\hline 0 & $2 \cdot 1$ & & & & & & \\
\hline $\mathbf{P}$ & 1.9 & & & & & & \\
\hline $\mathrm{Q}$ & 1.7 & & & & & & \\
\hline $\mathbf{R}$ & 1.5 & & & & & & \\
\hline $\mathbf{s}$ & $1 \cdot 3$ & $\mathbf{S}$ & $1 \cdot 3$ & & & & \\
\hline $\mathbf{T}$ & 1.25 & $\mathrm{~T}$ & 1.25 & $T$ & 1.25 & $T$ & $1 \cdot 25$ \\
\hline $\mathrm{U}$ & $1 \cdot 1$ & $\mathrm{U}$ & $1 \cdot 1$ & & & & \\
\hline$v_{\ddagger}^{\ddagger}$ & 0.55 & $v \ddagger$ & 0.55 & $\mathrm{~V} \ddagger$ & 0.55 & $V \ddagger$ & 0.55 \\
\hline
\end{tabular}

Benzyl alcohol dehydrogenase (BADH, $x y l B$ ) activity is expressed from pDK2-3090, pDK23092 and pDK2-3114 but not from pDK1-3059, and can thus be placed between coordinates $3 \cdot 4$ and $5 \cdot 5$.

Xylene oxygenase $(x y l A)$, which cannot be assayed in cell extracts, was located by complementation of PaW263, a mutant of PaWl (P. putida mt-2) with a nonfunctional $x y l A$ but with normal activities of the subsequent enzymes of the TOL pathway (Franklin \& Williams, 1980). When mobilized into PaW263, pDK1-3059, pDK 1-3060 and pDK1-3111 complemented it for growth on $m$-xylene, enabling the gene to be positioned between coordinates $4 \cdot 7$ and $8 \cdot 1$.

The location of the operator-promoter for the operon (OP1) was first found by Southern blotting using cloned DNA from the OP1 region of pWW0 as a probe. Confirmation of the role of this region as a functional necessity for inducible expression of the operon was obtained in PaW823. This strain contains pWW0-660, a deletion derivative of $\mathrm{pWW}$, which lacks the complete $x y l C A B$ operon but which has both regulatory genes $x y l S$ and $x y l R$ intact (Lebens \& Williams, 1985): as a result it will not grow on $m$-xylene. When pDK1-3059 and pDK1-3060 were mobilized into PaW823, BZDH activity was inducible by $m$-xylene but no inducible activity was found when pDK1-3042 was used. OP1 is therefore located between coordinates 10.3 and 10.8. The presence of pDK1-3059 and pDK1-3060 in PaW823 enables it to grow on $m$-xylene, but only very poorly due to the incomplete $x y l B$ gene on the two recombinants, which is only poorly compensated for by the low isofunctional BADH activity that is chromosomally encoded. However, the construction of the subclone pDK1-3119, containing the complete 


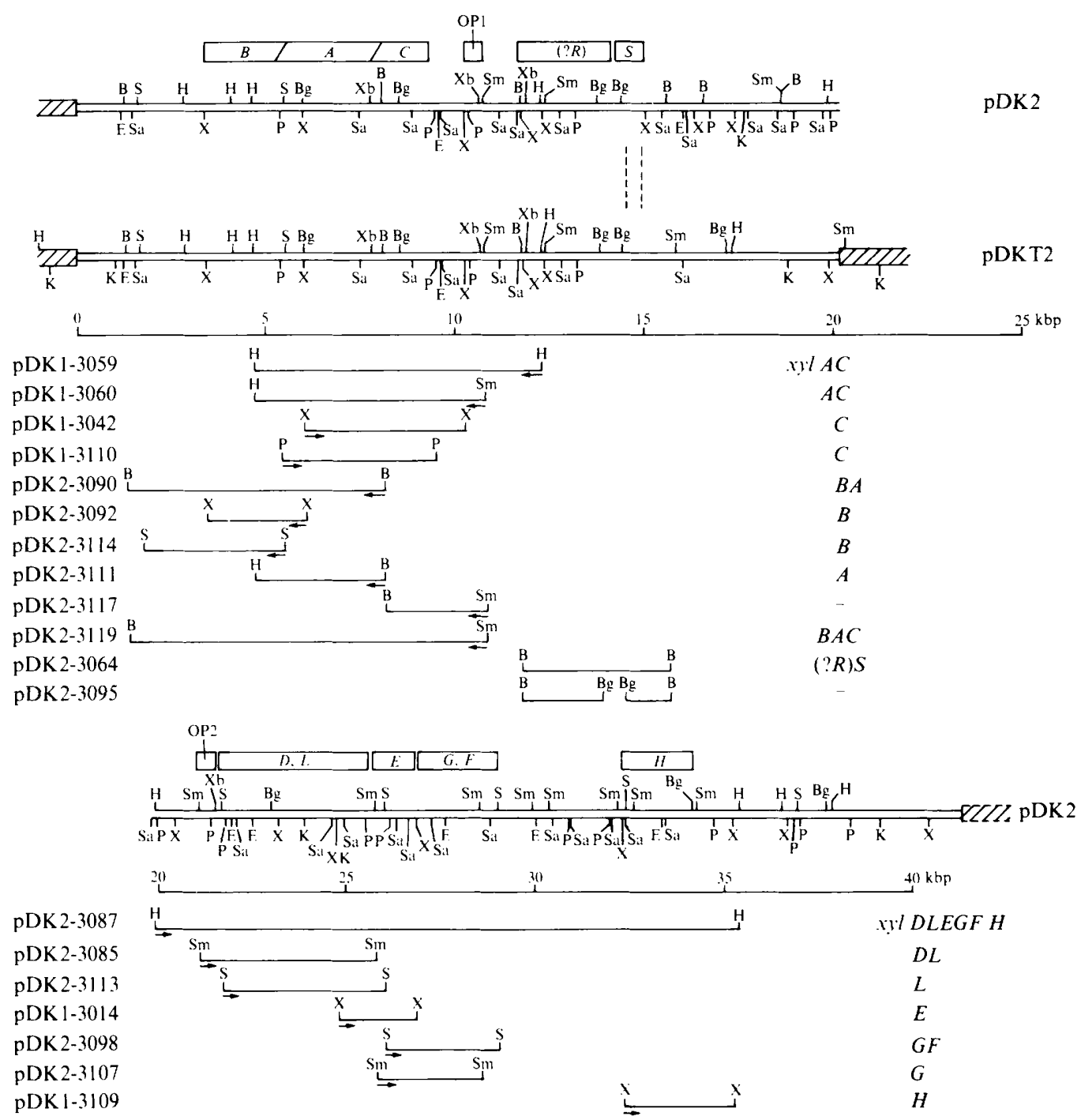

Fig. 3. Detailed physical maps showing the locations of restriction sites and catabolic genes on the complete $20 \mathrm{kbp}$ insert of pDKT1 DNA in the cointegrate plasmid pDKT2 and on the $40 \mathrm{kbp}$ insert of pDK1 DNA on the cointegrate plasmid $\mathrm{pDK} 2$. The various subclones constructed for this study are shown below the maps. The small arrows show the direction of transcription from the vector promoters in the recombinant plasmids carrying the cloned fragments. The abbreviations for restriction enzyme sites are as follows: B, BamHI ; Bg, BglII ; E, EcoRI; H, HindIII ; K, KpnI ; P, PstI ; S, SstI ; Sa, SalI ; Sm, SmaI $; \mathrm{X}, \mathrm{XhoI} ; \mathrm{Xb}, \mathrm{XbaI}$. OP1 and OP2 are the operator-promoter regions at the start of each operon; the locations of OP2 and $x y l R$ are only tentatively located on the basis of the similarity in restriction sites and homology to the OP2 and $x y l R$ regions of pWW 53-4 and pWW0 (Keil et al., 1985b). The righthand column indicates the genes which have been definitely located on the corresponding subclones. The vertical dotted lines indicate the area where pDK2 and pDKT2 diverge, presumably as a result of the deletion which gave rise to the formation of pDKT1 from pDK1. 
Table 3. Specific activities of the enzymes of the 'upper pathway' operon in P. putida and E. coli Enzyme activities are expressed as milliunits (mg protein) ${ }^{-1}$.

\begin{tabular}{|c|c|c|c|c|c|}
\hline Plasmid & Host* & Inducer & BADH & BZDH & $\begin{array}{c}x y l A \\
\text { complementation† } \dagger\end{array}$ \\
\hline None & E. coli & None & 3 & $<1$ & ND \\
\hline \multirow{2}{*}{ pDK1 } & HS1 & $m$-Xylene & 322 & 39 & ND \\
\hline & & None & 13 & 4 & ND \\
\hline \multirow[t]{2}{*}{ pDK2 } & PaW630 & $m$-Xylene & 127 & 33 & ND \\
\hline & & None & 13 & 5 & ND \\
\hline \multirow[t]{2}{*}{ pDKT1 } & PpCTl & Toluene & 460 & 85 & ND \\
\hline & & None & 17 & 4 & ND \\
\hline \multirow[t]{2}{*}{ pDKT2 } & PaW637 & Toluene & 138 & 92 & ND \\
\hline & & None & 23 & 5 & ND \\
\hline \multirow[t]{2}{*}{ pWW0-660 } & P. putida & $m$-Xylene & 15 & 9 & ND \\
\hline & & None & 13 & 7 & ND \\
\hline \multirow[t]{3}{*}{ pDK 1-3042 } & E. coli & None & 4 & 13 & ND \\
\hline & P. putida & $m$-Xylene & 19 & 10 & - \\
\hline & & None & 12 & 6 & ND \\
\hline \multirow[t]{3}{*}{ pDK1-3059 } & E. coli & None & 4 & 9 & ND \\
\hline & P. putida & $m$-Xylene & 10 & 125 & + \\
\hline & & None & 14 & 18 & ND \\
\hline \multirow{3}{*}{ pDK $1-3060$} & E. coli & None & 4 & 16 & ND \\
\hline & P. putida & $m$-Xylene & 11 & 144 & + \\
\hline & & None & 11 & 9 & ND \\
\hline pDK2-3090 & E. coli & None & 450 & $<1$ & ND \\
\hline pDK2-3092 & E. coli & None & 644 & $<1$ & ND \\
\hline pDK $1-3110$ & E. coli & None & 4 & 11 & ND \\
\hline \multirow{3}{*}{ pDK 1-3111 } & E. coli & None & 4 & $<1$ & ND \\
\hline & P. putida & $m$-Xylene & 14 & 8 & + \\
\hline & & None & 13 & 6 & ND \\
\hline pDK2-3114 & E. coli & None & 190 & $<1$ & ND \\
\hline pDK $1-3117$ & E. coli & None & 4 & $<1$ & ND \\
\hline \multirow{3}{*}{ pDK2-3119 } & E. coli & None & 246 & 15 & ND \\
\hline & P. putida & $m$-Xylene & 443 & 132 & ND \\
\hline & & None & 47 & 10 & ND \\
\hline
\end{tabular}

$x y l C A B$ operon together with OP1, and its mobilization into $\mathrm{PaW} 823$ produced a strain which grew well on $m$-xylene and contained high induced levels of BADH and BZDH (Table 3).

Location of genes of the meta pathway operon

Recombinant plasmid pDK2-3087, with the $15.5 \mathrm{kbp}$ insert of HindIII fragment A, conferred the ability to grow on $m$-toluate upon plasmid-free $P$. putida, thus showing that it carried the entire meta-cleavage pathway from catechol to pyruvate and acetaldehyde and possibly also from benzoate (or $m$-toluate) to catechol (or 3-methylcatechol), although this latter transformation could be carried out by the isofunctional, chromosomally-coded enzymes.

Table 4 summarizes the results of assays of meta pathway enzymes in strains carrying cloned inserts of pDK2 DNA.

Catechol 2,3-oxygenase $(\mathrm{C} 23 \mathrm{O}, x y l E)$ activity was located on a small XhoI fragment delineated by coordinates 25 and 26.8 (pDK1-3014). Both 2-hydroxymuconic semialdehyde hydrolase (HMSH, $x y l F$ ) and 2-hydroxymuconic semialdehyde dehydrogenase (HMSD, $x y l G$ ) were located between coordinates 26 and 29 on plasmid pDK2-3098. However, only HMSD activity was expressed from the recombinant with the $S m a \mathrm{I}$ insert, pDK2-3107, showing that $x y l F$ is downstream of $x y l G$ and extends past coordinate 28.6 .

4-Oxalocrotonate tautomerase (4OT, $x y l H)$ activity was detected in strains carrying pDK13109 , which has an $X h o I$ insert which maps between coordinates $32 \cdot 2$ and $35 \cdot 2$. 
Table 4. Specific activities of the enzymes of the meta pathway operon in strains of E. coli and P. putida

Enzyme activities are expressed as milliunits (mg protein) $)^{-1}$.

\begin{tabular}{|c|c|c|c|c|c|c|}
\hline Plasmid & Host ${ }^{*}$ & Inducer & $\mathrm{C} 23 \mathrm{O}$ & HMSD & HMSH & $4 \mathrm{OT}$ \\
\hline \multirow{3}{*}{$\begin{array}{l}\text { None } \\
\text { pDK1 }\end{array}$} & E. coli & None & $<0.1$ & $<0 \cdot 1$ & $<0 \cdot 1$ & $<100$ \\
\hline & HSI & $m$-Toluate & 160 & 39 & 57 & 110000 \\
\hline & & None & $1 \cdot 3$ & 0.9 & 0.8 & 400 \\
\hline \multirow[t]{2}{*}{ pDK2 } & PaW630 & $m$-Toluate & 125 & 25 & 39 & 25700 \\
\hline & & None & 1.2 & 0.3 & 0.5 & ND \\
\hline \multirow{2}{*}{ pDK 1-3014 } & E. coli & None & 40 & $<0.1$ & $<0 \cdot 1$ & ND \\
\hline & P. putida & None & 5 & $<0.1$ & $<0 \cdot 1$ & ND \\
\hline \multirow[t]{3}{*}{ pDK 2-3087 } & E. coli & None & 2 & 0.5 & 0.8 & ND \\
\hline & P. putida & $m$-Toluate & $5 \overline{6}$ & 24 & 12 & ND \\
\hline & & None & 21 & 11 & 7 & ND \\
\hline \multirow{3}{*}{ pDK 2-3091 } & E. coli & None & 1 & 0.5 & 1.4 & ND \\
\hline & P. putida & $m$-Toluate & 238 & 98 & 106 & 143000 \\
\hline & & None & 28 & 11 & 10 & 7000 \\
\hline \multirow{2}{*}{ pDK2-3098 } & E. coli & None & $<0.1$ & $1 \cdot 3$ & $2 \cdot 5$ & ND \\
\hline & P. putida & None & $<0.1$ & 1.5 & $1 \cdot 2$ & ND \\
\hline \multirow[t]{3}{*}{ pDK2-3100 } & E. coli & None & 2 & 0.5 & 0.1 & ND \\
\hline & P. putida & $m$-Toluate & 57 & 25 & 21 & ND \\
\hline & & None & 25 & 12 & 12 & ND \\
\hline \multirow{3}{*}{$\begin{array}{l}\text { pDR } 1-3107 \\
\text { pDK } 1-3109\end{array}$} & E. coli & None & $<0.1$ & $3 \cdot 5$ & $<0 \cdot 1$ & ND \\
\hline & E. coli & None & ND & ND & ND & 2300 \\
\hline & $P$. putida & None & ND & ND & ND & 7300 \\
\hline
\end{tabular}

The first activities of the operon, benzoate oxygenase $(x y l D)$ and benzoate cis-diol dehydrogenase $(x y l L)$, which together convert benzoate to catechol, were shown to reside on $H$ indIII-A and were more precisely positioned as follows. $E$. coli containing either pDK2-3085 or pDK2-3113, plasmids with overlapping inserts (Fig. 3) were streaked onto Isosensitest agar (Oxoid) containing $5 \mathrm{~mm}-m$-toluate. In the case of only the former plasmid, the colonies and surrounding agar developed a dark brown colour due to accumulation of 3-methylcatechol and its subsequent autoxidation; it follows that both $x y l D$ and $x y l L$ are between the SmaI sites at coordinates $21 \cdot 1$ and $25 \cdot 8$. The presence or absence of $x y l L$ was tested by mobilizing both plasmids separately into $\mathrm{PaW} 95$, a plasmid-free mutant of $\mathrm{PaW} 1$ which has a mutation in the chromosomal benzoate cis-diol dehydrogenase but has a functional chromosomal benzoate oxygenase and does not grow on benzoate. Both pDK2-3085 and pDK2-3113 restored the ability of $\mathrm{PaW} 95$ to grow on benzoate, showing the presence of $x y l L$ on both. The order of the two genes in this area of the plasmid must be $x y l D L$.

\section{Identification of regulatory gene $x y l S$}

As can be seen in Fig. 3, the point at which the TOL insert in pDKT2 diverges from that of pDK 2 is beyond the two $B g l I \mathrm{I}$ sites at 13.8 and 14.4 respectively but before the $X h o$ I site in pDK2 at 15.1. Two similar adjacent $B g I I I$ sites occur in the $x y l S R$ region of both pWW0 and pWW53-4 (Keil et al., 1985b). A Southern blot, using as the probe a small subclone of pWW0 DNA internal to its $x y l S$ gene (a gift of F. C. H. Franklin) hybridized to the BamHI subclone pDK2-3064 as well as to the HindIII-Kn fragment of pDKT2. A construction was made by recloning the BamHI insert of pDK2-3064 into the unique BamHI site which is in the vector part of plasmid pDK2-3087, forming plasmid pDK2-3091. A second such construct was made by first deleting the $600 \mathrm{kbp}$ between the two Bg/II sites in the insert of pDK2-3064 thus forming pDK2-3095: the shortened insert was then cut out with BamHI and religated into the same single BamHI site in pDK2-3087 to form pDK2-3100: the rationale for making this deletion is that if the two $B g / I \mathrm{I}$ sites are in the same positions as in the $x y l S R$ region of pWW0 then its 
deletion removes the complete intergenic region together with part of each coding region for the two regulatory proteins, thus inactivating them (Spooner et al., 1986).

All three plasmids, pDK2-3087, carrying the start of the meta pathway operon, pDK2-3091, with the additional insert of putative $x y l S$ DNA, and pDK2-3100, with the possible deletion in the putative regulatory genes, were mobilized into plasmid-free PaW130 and assays were done to detect induction of C23O, HMSH and HMSD in the presence and absence of $m$-toluate, the inducer which acts in combination with the $x y l S$ gene product (Worsey et al., 1978; Inouye et al., 1981). There was an induction by $m$-toluate of 8- to 10 -fold in the case of pDK2-3091 but not with the other plasmids, showing that there is a $x y l S$ gene which spans one or both of the two BglII sites in pDK2-3064. Subsequent initial studies not presented here have shown that the gene products of $x y l H, x y l I$ and $x y l J$ are also induced by $m$-toluate from pDK2-3091.

It is worth noting that in $P$. putida the recombinant plasmid pDK2-3091, with the complete regulated meta pathway operon, supported a noticeably faster rate of growth on $m$-toluate than did pDK2-3087, which did not have the additional $x y l S$ insert. This is doubtless due to the higher specific activities of the enzymes expressed (Table 4).

\section{Attempts to locate the regulatory gene $x y l R$}

We have tried to do similar experiments to show that the region around the two $B g I I I$ sites also carries a functional $x y l R$ gene which in combination with $m$-xylene can initiate transcription of the $x y l C A B$ operon from OP1. Attempts to construct a single recombinant plasmid carrying the insert of pDK2-3064 (the putative $x y l S R$ region) and that of $\mathrm{pDK} 1-3119$ (the complete $x y l C A B$ operon) have not been successful. However, Southern blotting has shown that the pDK2-3064 insert displays strong homology with the $x y l R$ region of pWW53-4 and enzyme assay demonstrates that toluene and $m$-xylene induce both BADH and BZDH in strains containing pDK2 and pDKT2 (Table 3), showing that a regulator gene must reside somewhere on the TOL DNA inserts of those plasmids. The localization of $x y l R$ will require further investigation.

\section{DISCUSSION}

Pseudomonas putida HS1 containing the TOL plasmid pDK1 was originally isolated from soil in Minnesota, USA (Kunz \& Chapman, 1981), geographically remote from the sources of the other two carefully mapped TOL plasmid-containing strains, P. putida mt-2, isolated in Japan in the 1950 s and containing the archetype pWW0, and P.putida MT53, host to pWW53, isolated in North Wales. Yet the physical organization of the catabolic genes on $\mathrm{pDK} 1$ reinforces the features which have already been shown by the comparison between pWW0 and the RP4::pWW53 cointegrate plasmid pWW53-4 (Keil et al., 1987b).

Firstly, the pathway genes on all three plasmids are organized in three separate units, the 'upper pathway' operon $x y l C A B$, the meta pathway operon, $x y l D L E G F(J, I, K) H$ and a regulatory cluster of two genes $x y l S R$. Within each of the three units, the gene order is absolutely conserved, as far as can be ascertained, given that all the meta pathway genes have not been completely localized on $\mathrm{pWW} 53-4$ or $\mathrm{pDK} 1$. In all three plasmids the identity of gene order within the three units is reinforced by a high degree of conservation of restriction sites in what appear to be the same positions. This latter can only be a rough estimate because restriction mapping is obviously not sufficiently accurate to be able to determine whether two sites for the same enzyme on two separate strands of DNA are in identical positions on both. However, there is a remarkable coincidence in the order of the cutting sites for the enzymes used for the three TOL plasmids. Thus within the coding regions for the meta pathway operon, 15 of the 29 sites found on $\mathrm{pDK} 2$ (and therefore by inference on pDK1) are in apparently the same position on pWW0 and 16 are shared with pWW53. The similarity between the $x y l C A B$ operons of pDK1 and pWW53-4 is even more remarkable: all of the 20 restriction sites found on pDK1 are also found on the corresponding region of pWW53, and there is but one additional site on pWW53 not found on pDK1.

The strong homology implied by the same gene order and shared restriction sites is borne out by hybridization, and results not presented here show that within the three units on the three 
plasmids there is very strong colinearity in homology: in fact in the early stages of this work we used Southern blotting with already characterized fragments of pWW0 or pWW53 as a means of facilitating our identification of coding regions of pDK1.

The similarity of the genes is complemented by the apparent similarity in the regulation. Not only are both the OP1 region, upstream of the $x y l C A B$ operon, and the region identified as $x y l S$ highly conserved but there is also homology on pDK1 to parts of pWW53-4 and pWW0 which have been shown to have OP2 and $x y l R$ functions on those plasmids, but which we have not yet been able to show have such a function on pDK1. Additionally there is a degree of functional cross-reaction between the regulatory elements on the three plasmids. Thus in this work and in our study of pWW53 (Keil et al., 1987a) we have demonstrated that the product of the regulatory gene $x y l R$ on $\mathrm{pWW} 0$ can cause induction downstream of the OP1 operator-promoter regions on pWW53 and pDK1.

There is therefore considerable evidence for a high degree of conservation of the catabolic genes on these three plasmids in spite of their very diverse geographical origins, but it is also clear that the conservation exists only within the coding regions and there is no evidence from either restriction site analysis or from hybridization studies that the homology continues into the non-catabolic regions of the plasmids.

What is perhaps most surprising about the comparison of the three plasmid-encoded pathways is that the relative positions of the three modules which made up the TOL DNA on each are totally different. If the relevant DNA is oriented with the $x y l C A B$ operon transcribed from left to right the three plasmids read as follows, with the arrows denoting the directions of transcription: pWW0 $(\rightarrow C A B)(\rightarrow D L E G F J K I H)(S R)$; pWW53-4 $(\rightarrow D L E G F(J, K) I H)(S R)-$ $(\rightarrow C A B)$; pDK1 $(H(J, K, I) F G E L D \leftrightarrow)(S(R ?))(\rightarrow C A B)$ (Fig. 4). It is clear therefore that the acquisition of the complete set of TOL genes by the three replicons has not been the straightforward recombinational transfer of a continuous sequence of DNA.

It has been shown that $56 \mathrm{kbp}$ of $\mathrm{pWW} 0$ encompassing the entire regulated TOL region can move from its plasmid location into the chromosome (Jeenes \& Williams, 1982) and can then recombine with other plasmid replicons, thus forming novel TOL plasmids. This observation is in remarkable coincidence with the finding that $P$. putida MW1000 is the only wellauthenticated example of a soil isolate carrying the toluene/xylene catabolic route which has the genes located, not in a plasmid, but on the chromosome (Sinclair et al., 1986) and the evidence from Southern hybridization is that the catabolic DNA of this strain is identical in its digestion by restriction enzymes to that of $\mathrm{pWW} 0$. These two findings, taken together with the very strong recent evidence that the TOL genes of pWW0 reside on a $56 \mathrm{kbp}$ transposon designated Tn4561 (Tsuda \& Iino, 1987), might suggest that different TOL plasmids arose by the transposition of that $56 \mathrm{kbp}$ element between replicons in much the same way as many of the R-plasmids have evolved by acquisition of recognizable transposable elements such as $\operatorname{Tn} 1$.

The differences between the gene organization on pDK1 and pWW53 and that on pWW0 seem to suggest a less simple situation. If they did acquire the TOL genes via a transposon such as Tn4561 found on $\mathrm{pWW} 0$, then there has been considerable rearrangement of the operons and the regulatory genes subsequently, and probably a loss of the transposition function, since there is no apparent similarity in the DNA flanking the catabolic region where the transposition genes on pWW0 have been shown to reside (Tsuda \& Iino, 1987). An alternative hypothesis might be that the pWW 53 and pDK 1 replicons had acquired the TOL operons at different times and from different locations. This is a plausible possibility since either operon could exist singly as a functional metabolic unit of selective advantage to its host cell. This is well demonstrated by this study in particular since pDKT1 and pDKT2 are both plasmids formed in vivo which carry only the upper pathway operon and confer the ability to convert toluene to benzoate which is then further metabolized by the chromosomal route. The further acquisition by such a plasmid, carrying the upper pathway operon, of a second operon encoding the meta pathway sequence would be selectively advantageous to hosts since it would make available the methyl-substituted analogues as growth substrates. It could be argued that the spontaneous dissociation of pDK1 upon benzoate selection (Kunz \& Chapman, 1981) is perhaps a reflection of a modular construction in the first place. 

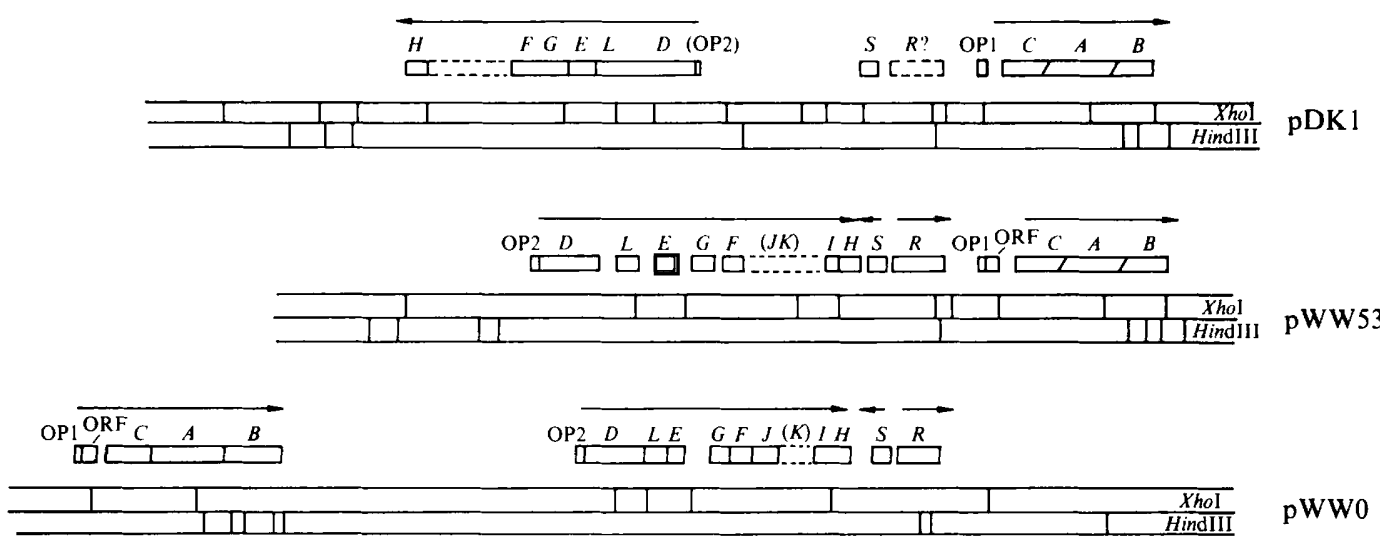

pWW0

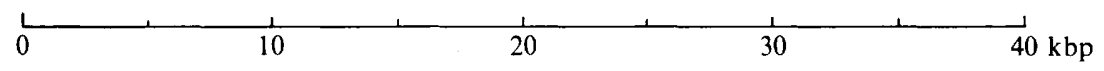

Fig. 4. Comparison of the locations of the $x y l$ genes on TOL plasmids pDK1, pWW0 and pWW53-4. Transcription of the operons and genes is indicated by the arrows. The positions of the genes on pWW0 are taken from a number of references including Harayama et al. (1984) and Lebens \& Williams (1985) and that of pWW53-4 from Keil et al. (1987b). ORF, open reading frame.

Furthermore, recent results indicate that the meta pathway operons which form the second regulons of the pathways for naphthalene dissimilation on plasmids NAH7 (Harayama et al., 1987) and pWW60-1 (Assinder \& Williams, 1988) share a common ancestry with the same sequence on TOL plasmids and that the naphthalene pathway might also have evolved by the separate evolution of its two operons followed by their coacquisition by a vector plasmid.

Two other features of pDK1 are shared with pWW0 and pWW53. The first is its segregation of deletion mutants during growth on benzoate, although in each case the nature of the deletion and the resulting phenotypes of the hosts are unique to each plasmid. In the case of pDK1 the point at which the deletion gives rise to loss of the meta pathway genes in the formation of pDKT1 is close to the regulatory gene $x y l S$ at coordinate $14.8 \pm 0.3$ (Fig. 3). The second property common to the TOL plasmids pDK1, pWW53 and pWW0 is the ease with which they form cointegrate plasmids with RP4 (Nakazawa et al., 1978; Keil et al., 1985b). Some of the RP4::pWW0 cointegrates such as pTN2 probably contain the $56 \mathrm{kbp}$ transposed into the Rplasmid, but others involve stretches of DNA of different lengths (Lehrbach et al., 1982). In the case of pWW53 and pDK1, and its derivatives, we appear to get a wide variety of cointegrate plasmids which contain inserts of TOL DNA of differing sizes in a complete RP4 (Pickup, 1984; unpublished results). In the case of the two plasmids described here the integration sites in RP4 are not identical but both share what appears to be a common terminus of the pDK1 DNA. Whether this is fortuitous or whether it represents the location of a recombinational hotspot on pDK1 will have to be left to further investigations.

The authors would like to thank Dr D. A. Kunz for the gift of strains HS1 and PpCT1 and for help and advice in the early stages of this work.

\section{REFERENCES}

Assinder, S. J. \& Williams, P. A. (1988). Comparison of the meta pathway operons on NAH plasmid pWW60-22 and TOL plasmid pWW53-4 and its evolutionary significance. Journal of General Microbiology 134, 2769-2778.

F. C. H., Bagdasarian, M. M., Frey, J. \& Timmis,

K. N. (1981). Specific purpose plasmid cloning vectors. II. Broad host range, high copy number RSF1010-derived vectors and a host:vector system for gene cloning. Gene 16, 237-247.

Franklin, F. C. H. \& Williams, P. A. (1980). Construction of a partial diploid for the degradative 
pathway encoded by the TOL plasmid (pWW0) from Pseudomonas putida $\mathrm{mt}-2$ : evidence for the positive nature of the regulation by the $x y l R$ gene. Molecular and General Genetics 177, 321-328.

GRINTER, N. J. (1983). A broad host range cloning vector transposable to various replicons. Gene 21, 133-143.

Harayama, S., Lehrbach, P. R. \& Timmis, K. N. (1984). Transposon mutagenesis analysis of metacleavage pathway operon genes of the TOL plasmid of Pseudomonas putida mt-2. Journal of Bacteriology 160, 251-255.

Harayama, S., Rekik, M., Wasserfallen, A. \& BAIROCH, A. (1987). Evolutionary relationship between catabolic pathways for aromatics: conservation of gene order and nucleotide sequences for catechol oxidation genes of pWW0 and NAH7 plasmids. Molecular and General Genetics 210, 241247.

Holmes, D. S. \& Quigley, M. (1981). A rapid boiling method for preparation of bacterial plasmids. Analytical Biochemistry 114, 193-197.

InOUYe, S., Nakazawa, A. \& NaKazawa, T. (1981). Molecular cloning of gene $x y l S$ of the TOL plasmid: evidence for the positive regulation of the $x y l D E F G$ operon by $x y l S$. Journal of Bacteriology 148, 413-418.

JeEnes, D. J. \& Williams, P. A. (1982). Excision and integration of degradative pathway genes from TOL plasmid pWW0. Journal of Bacteriology 150, 188194.

Keil, H., Lebens, M. R. \& Williams, P. A. (1985a). TOL plasmid pWW15 contains two non-homologous, independently regulated catechol 2,3-oxygenase genes. Journal of Bacteriology 163, 248-255.

KeIL, H., KeIL, S., PickuP, R. W. \& Williams, P. A. $(1985 b)$. Evolutionary conservation of genes coding for meta pathway enzymes within TOL plasmids pWW0 and pWW53. Journal of Bacteriology 164, 887-895.

Keil, H., Saint, C. M. \& Williams, P. A. (1987a). Gene organisation of the first catabolic operon of TOL plasmid pWW 53: production of indigo by the $x y l A$ gene product. Journal of Bacteriology 169, 764770.

Keil, H., KeIl, S. \& Williams, P. A. (1987b). Molecular analysis of regulatory and structural $x y l$ genes of the TOL plasmid pWW53-4. Journal of General Microbiology 133, 1149-1158.

Kunz, D. A. \& Chapman, P. J. (1981). Isolation and characterization of spontaneously occurring TOL plasmid mutants of Pseudomonas putida HS1. Journal of Bacteriology 146, 952-964.

LANKA, E., LURZ, R. \& FURSTE, J. P. (1983). Molecular cloning and mapping of $S p h I$ restriction fragments of plasmid RP4. Plasmid 10, 303-307.

Lebens, M. R. \& Williams, P. A. (1985). Complementation of deletion and insertion mutants of TOL plasmid pWW0: regulatory implications and location of $x y l C$ gene. Journal of General Microbiology 131, 3261-3269.

Lehrbach, P. R., Ward, J., Meulien, P. \& Broda, P. (1982). Physical mapping of TOL plasmids pWW0 and pND2 and various R plasmid-TOL derivatives from Pseudomonas spp. Journal of Bacteriology 152, 1280-1283.
Maniatis, T., Fritsch, E. F. \& SAMbrooK, J. (editors) (1982). Molecular Cloning : a Laboratory Manual, pp. 94-148. Cold Spring Harbor, NY: Cold Spring Harbor Laboratory.

NaKazaWA, T. \& Yokota, T. (1973). Conjugal transfer of benzoate pathway genes in Pseudomonas arvilla $\mathrm{mt}-2$. Japanese Journal of Bacteriology $28,46$.

Nakazawa, T., Hayashi, E., Yokota, T., Ebina, Y. \& NAKAZAWA, A. (1978). Isolation of TOL and RP4 recombinants by integrative suppression. Journal of Bacteriology 134, 270-277.

PICKUP, R. W. (1984). Physical and structural properties of TOL plasmids in Pseudomonas. PhD thesis, University of Wales.

PrentKI, P. \& KirsCh, A. M. (1982). A modified pBR322 vector with improved properties for the cloning, recovery and sequencing of blunt-ended DNA fragments. Gene 17, 189-196.

Sala-Trepat, J.-M. \& Evans, W. C. (1971). The meta cleavage of catechol by Azotobacter species: 4oxalocrotonate pathway. European Journal of Biochemistry 20, 400-413.

Sinclair, M. I., MaXwell, P. C., Lyon, B. R. \& Holloway, B. W. (1986). Chromosomal location of TOL plasmid DNA in Pseudomonas putida. Journal of Bacteriology 168, 1302-1308.

SOUTHERN, E. M. (1975). Detection of specific sequences among DNA fragments separated by gel electrophoresis. Journal of Molecular Biology 98, 505-518.

SPOONER, R. A., Lindsay, K. \& Franklin, F. C. H. (1986). Genetic, functional and sequence analysis of the $x y l R$ and $x y l S$ region of the TOL plasmid pWW0. Journal of General Microbiology 132, 13471358.

TsudA, M. \& IrNo, T. (1987). Genetic analysis of a transposon carrying toluene degrading genes on TOL plasmid pWW0. Molecular and General Genetics 210, 270-276.

Wheatcroft, R. \& Williams, P. A. (1981). Rapid methods for the study of both stable and unstable plasmids in Pseudomonas. Journal of General Microbiology 124, 433-437.

Williams, P. A. \& MurRay, K. (1974). Metabolism of benzoate and the methylbenzoates by Pseudomonas putida (arvilla) $\mathrm{mt}-2$ : evidence for the existence of a TOL plasmid. Journal of Bacteriology 120, 416-423. Williams, P. A. \& Worsey, M. J. (1976). Ubiquity of plasmids in coding for toluene and xylene metabolism in soil bacteria: evidence for the existence of new TOL plasmids. Journal of Bacteriology 125, 818828.

Worsey, M. J. \& WilliaMs, P. A. (1975). Metabolism of toluene and xylenes by Pseudomonas putida (arvilla) mt-2: evidence for a new function of the TOL plasmid. Journal of Bacteriology 124, 7-13.

Worsey, M. J., Franklin, F. C. H. \& Williams, P. A. (1978). Regulation of the degradative pathway enzymes coded for by the TOL plasmid (pWW0) from Pseudomonas putida mt-2. Journal of Bacteriology 134, 757-764.

YANO, K. \& NishI, T. (1980). pKJ1, a naturally occurring conjugative plasmid coding for toluene degradation and resistance to streptomycin and sulphonamides. Journal of Bacteriology 143, 552-560. 